\title{
Participation Motives of Saudi Arabian School Children towards Physical Activities and Sports: A Comparative Study
}

\author{
Mohammed Hamdan Hashem Mohammed", Varghese C Antony \\ Department of Physical Education, King Fahd University of Petroleum and Minerals, Saudi Arabia
}

Copyright $(\mathcal{C} 2015$ by authors, all rights reserved. Authors agree that this article remains permanently open access under the terms of the Creative Commons Attribution License 4.0 International License

\begin{abstract}
The objective of this study was to identify and compare the participation motives of school children towards engagement in physical activity. Two hundred and eighty students $\left(\mathrm{M}_{\mathrm{age}}=17.65 \pm 0.95\right.$ years $)$ were selected from two different types of schools, namely government school $(\mathrm{N}=134)$ and private school $(\mathrm{N}=146)$, Dhahran, Saudi Arabia. The instrument used to collect the data was Motivation for Physical Activities Measure- Revised by (Ryan et al., 1997). Ranking order was applied to identify the 'most important reasons' and 'least important reasons' for participation, and $\mathrm{t}$ - test was applied to compare means between the groups. Government and private school children showed higher mean values on interest/enjoyment and competence. Significant difference was observed on interest/enjoyment and fitness factor among school children. No significant difference was observed on competence, appearance, and social factors. Government school children ranked three important reasons for participation in physical activities as 'because I wanted to be physically fit', 'because I wanted to look or maintain weight so I look better', and 'because I wanted to maintain my physical well-being'. Whereas private school children ranked best three reasons for engagement as, 'because I want to look or maintain weight so I look better', because I want to improve my appearance, because I wanted to be physically fit'. The least important reason for participation was social factors for both types of school children.
\end{abstract}

Keywords Participation Motivation, Physical Activity, Private High School, Government High School, Fitness

\section{Introduction}

Motivation is a complex phenomenon that is impossible to simply subsume under a single model [1]. Understanding why individuals participate in sport is not a simple matter. One of the most important issues is that people have many reasons for getting involved, and some of their reasons change according to the situations. Drawing on the excellent review of literature [2-10], the reason sports people give for participating and dropping out are multiple and diverse. Weiss and Petlickhoff [11], for example, categorized the major motives for participation into competence (e.g. to learn and improve skills), affiliation (e.g. to make friends be part of a team), fitness (e.g., to be physically active, get in shape), and fun. Some past research indicates that people have different achievement goals with regard to sports participation $[12,13]$ and it is reasonable to suggest that their attainment is a constituent of enjoyment. Among the several reasons given for decreased interest and a subsequent withdrawal from sport was lack of fun, issues with the coach, the time commitment required, lack of playing time, overemphasis on winning, and greater interest in other activities [14].

Children of the modern society are aware of the benefits of engaging in physical activity and sports which aims at improving physical and mental health [15-17]. Several studies have demonstrated that the motives given for sports participation are not only the physical aspects, but a number of other factors, such as weight control and appearance, stress and mood management, competition and enjoyment, fun and excitement [18-22]. Additionally, motives are quite different from one to another for several factors, i.e., age and gender [22-24]. The Canada Fitness Survey [25] provides an insight into the motivations of Canadian youth to participate in physical activity and the results showed the main reasons for being active were fun, feeling better, weight control, flexibility and challenge. Motivations to engage in physical activity often relate to physical, mental health, weight management and fitness. Motives are important determinants of exercise participation.

Physical activity has both preventive and curative effects $[26,27]$. Sport participation has been proven to have great positive effect on the human body, and strong motivations also make people to participate in a particular sport continuously. But not all positive effects are strong enough to make people participate in the sports. Studies around the world have shown that young people are not as physically 
active as they need and should be to enjoy the health benefits of physical activity [19,28-34]. It is clear that more developmental research is called for to understand variations in reasons for participating in and withdrawing from sport and physical activity. However, different research studies across the world show some cultural differences in the psychological meaning of sport in different cultures [35].

It is a proven fact that physical activities help in promoting an individual's health and healthy living, especially in this very busy world. Definitely, participation in physical activities is considered as fulfilling a domain of the healthy lifestyles. When children are involved in sports and physical activities, it was noticed that motivation to participate and gain many physical, psychological and health benefits attained were maximum. It is the right time for us to motivate the children who were not involved in physical activities at least at school level. While looking at these reviews it was learned that no similar research studies has been published in the field participation motives of school children towards physical activities in Saudi Arabia. So this study was taken up to identify and compare the participation motives of school children of Saudi Arabia and it was hypothesized that there would be no significant difference between government and private school children on the participation motives.

\section{Materials and Methods}

\subsection{Participants and Procedure}

The participants were 280 school children, boys aged between 15-19 years $\left(\mathrm{M}_{\mathrm{age}}=17.65\right.$ years) selected from two different types of schools, namely government school $(\mathrm{N}=134)$ and private school $(\mathrm{N}=146)$, Dhahran, Saudi Arabia for the session 2013 - 2014. We have randomly selected 3 government schools and 3 private schools from the list of top 10 schools of eastern province with regard to academics and facilities. Saudi Arabia has very harsh climatic conditions especially during summer. Though these selected schools have excellent indoor facilities for physical activities, we have collected the data during November 2013. After acquiring the permission to conduct the study, the students were informed the purpose of the study and were assured that participation in this study will be completely voluntary. No motivational techniques were used to collect the data. The questionnaire was distributed in the class room setting. Participants were given sufficient time to complete the questionnaire. All the participants completed a 30 item survey assessing their participation motives of physical activity and sports. The dependent variables were participation motive factors, namely enjoyment/interest, competence, appearance, fitness, and social. 24 questionnaires of government schools and 7 questionnaires from private schools were found incomplete, which were excluded from the study. Expat students were also excluded from this study. The main difference identified between government and private schools were: Only Saudi students studied in the government schools, tuition fees was free for Saudis and not much of cultural variations were seen; whereas private schools comprised of many expat students, with a multi-cultural atmosphere and high tuition fees.

\subsection{Instrument}

Motivation for Physical Activities Measure- Revised [36] English version was administered to collect the data. The MPAM-R contains 30 items and its responses to each item were recorded on a 7-point scale ranging from 1 (not at all true for me) to 7 (very true for me). It contains five participation motive factors, namely, competence-challenge motives (e.g., "I like physical challenges"), appearance motives (e.g., "I want to improve my appearance"), social motives (e.g., "I want to meet new people"), fitness-health motives (e.g., "I want to maintain my physical strength") and enjoyment-interest motives (e.g., "I enjoy this activity"). This instrument has demonstrated reliability for each factor with Cronbach's $\alpha$ ranging from .78 to .92 [36]. A demographic questionnaire obtained general individual information like (name, age, height, weight, BMI, class of study etc).

\subsection{Statistical Analysis}

Prior to the statistical analyses data screening was undertaken to check the missing values and ensure that the values were within the expected range. Descriptive statistics mean and standard deviation was calculated for government and private school children on five motivating factors. Ranking order was applied to investigate the 'most important reasons' and 'least important reasons' for participation motivation. The ranking of reasons was calculated on the basis of response to the highest score ' 7 ' (very true for me). The t-ratio was employed to compare the significant difference of participation motivation between government and private school children. Data were analysed using SPSS software (version 17.0) and the criterion for statistical difference was set at 0.05 level of confidence.

\section{Results}

Table 1 explained the demographic information of school children, which showed private school children having more weight and higher body mass index (BMI). According the World Health Organization (WHO) BMI $>24.99$ is overweight; private school children are overweight and government school children are having just normal weight.

Table 1. Demographic Information of Schools Children

\begin{tabular}{|c|c|c|}
\hline & $\begin{array}{c}\text { Government School } \\
(\mathrm{N}=134)\end{array}$ & $\begin{array}{l}\text { Private } \\
(\mathrm{N}=146)\end{array}$ \\
\hline Age (years) & 17.7 & 18.08 \\
\hline Weight $(\mathrm{kg})$ & 70.6 & 74.67 \\
\hline Height $(\mathrm{cm})$ & 171 & 170 \\
\hline BMI $\left(\mathrm{kg} / \mathrm{m}^{2}\right)$ & 23.94 & 25.56 \\
\hline
\end{tabular}


Table 2. Descriptive Statistics of Participation Motives of Government and Private School Children and the t-test $\left({ }^{*} \mathrm{p}<0.05\right)$

\begin{tabular}{|c|c|c|c|c|c|c|c|}
\hline Participation Motives Factors & \multicolumn{2}{|c|}{ Government School (N=134) } & \multicolumn{2}{|c|}{ Private School (N=146) } & \multicolumn{3}{c|}{ t- test } \\
\hline \multirow{2}{*}{ Interest/ Enjoyment } & $\mathrm{M}$ & $\mathrm{SD}$ & $\mathrm{M}$ & $\mathrm{SD}$ & $\mathrm{t}$ - value & Sig. \\
\cline { 2 - 8 } & 36.31 & 6.67 & 33.96 & 6.31 & 4.37 & $0.030^{*}$ \\
\hline Competence & 33.43 & 7.39 & 31.45 & 7.72 & 2.97 & 0.086 \\
\hline Appearance & 27.46 & 7.68 & 26.51 & 7.25 & 0.71 & 0.399 \\
\hline Fitness & 27.31 & 6.21 & 25.68 & 6.28 & 4.01 & $0.046^{*}$ \\
\hline Social & 19.22 & 6.94 & 19.14 & 7.16 & 0.03 & 0.861 \\
\hline
\end{tabular}

Table 2 shows that mean values of participation motives of school children wherein, government school children exhibited higher mean values in all five factors of motives than private school children. Further t-ratio revealed a significant difference between government and private schools on participation motives factor interest \& enjoyment $\mathrm{t}(278)=4.37$; $\mathrm{p}=0.030<$ 0.05). This finding indicated that government school children are more motivated by interest/enjoyment reason than the private school children. Another significant difference was observed on fitness factor $\mathrm{t}(278)=4.01 ; \mathrm{p}=0.046<0.05)$, where it was understood that government school children are actively motivated by the fitness reasons than private school children. However, no significant differences were observed in other factors of participation motives.

Table 3. Ranking Order of Reasons for Participation by Government and Private School Children

\begin{tabular}{|c|c|c|}
\hline $\begin{array}{l}\text { Statement: } \\
\text { I engage in sport/ physical activity------------------ }\end{array}$ & Government School & Private School \\
\hline Because I want to be physically fit. & 1 & 3 \\
\hline Because I want to look or maintain weight so I look better. & 2 & 1 \\
\hline Because I want to maintain my physical health and well-being & 3 & 4 \\
\hline Because I want to maintain my physical strength to live a healthy life. & 4 & 8 \\
\hline Because I like to do this activity. & 5 & 13 \\
\hline Because it's fun. & 6 & 5 \\
\hline Because I think it is interesting. & 7 & 10 \\
\hline Because I want to improve my cardiovascular fitness. & 8 & 14 \\
\hline Because I want to improve my appearance. & 9 & 2 \\
\hline Because I want to improve my body shape. & 10 & 6 \\
\hline Because I want to have more energy. & 11 & 12 \\
\hline Because it makes me happy. & 12 & 7 \\
\hline Because I enjoy this activity. & 13 & 9 \\
\hline Because I find this activity stimulating. & 14 & 19 \\
\hline Because I enjoy spending time with others doing this activity. & 15 & 11 \\
\hline Because I want to get better at my activity. & 16 & 16 \\
\hline Because I like engaging in activities which physically challenge me. & 17 & 28 \\
\hline Because I want to improve existing skills. & 18 & 17 \\
\hline Because I like the challenge. & 19 & 15 \\
\hline Because I like activities which are physically challenging. & 20 & 23 \\
\hline Because I want to obtain new skills. & 21 & 21 \\
\hline Because I want to be with my friends. & 22 & 22 \\
\hline Because I want to define my muscles so I look better. & 23 & 25 \\
\hline Because I want to keep-up my current skill level. & 24 & 18 \\
\hline Because I will feel physically unattractive if I don't. & 25 & 24 \\
\hline Because I want to be attractive to others. & 26 & 20 \\
\hline Because I like to be with others who are interested in this activity. & 27 & 27 \\
\hline Because I like the excitement of participation. & 28 & 26 \\
\hline Because I want to meet new people. & 29 & 29 \\
\hline Because my friends want me to. & 30 & 30 \\
\hline
\end{tabular}


Table 3 demonstrates the rank order of reasons for participation towards physical activity and sports expressed by government and private school children, Dhahran, Saudi Arabia. The ranking of items was calculated on the basis of response to the highest score ' 7 ' (very true for me). The four topmost reasons for participation expressed by government school children were mainly fitness factors- 'because I want to be physically fit', 'because I want to look or maintain weight so I look better', 'because I want to maintain my physical health and well-being', 'because I want to maintain my physical strength to live a healthy life'; whereas, the private school children ranked their reasons mainly as appearance factors- 'because I want to look or maintain weight so I look better', 'because I want to improve my appearance', 'because I want to be physically fit', 'because I want to maintain my physical health and well-being'. The least important reason for participation towards physical activity and sports expressed by both school children were social factors- 'because my friends want me to', 'because I want to meet new people', because I like the excitement of participation', 'because I like to be with others who are interested in this activity'.

\section{Discussion and Conclusions}

In this study, our objective was to identify and compare the participation motives of government and private school children of Saudi Arabia. The results exhibited that important reasons for participation for both types of school children are mostly interest and enjoyment factor and most studies confirm that interest towards the activity and enjoyment derived from the activity are among the main reasons [18-22,37-39]. It was observed during the data collection that the children from private school were inactive in their PE classes and in general the population was looking overweight comparing with government school children. It may be due to the socio-economic class of parents and the private schools give lots of stress on studies. This observation corroborates results from previous studies in terms of the concern for and dissatisfaction with the body image felt by young adults with overweight and obesity [40,41].

The least important reason for participation motives were social factors for both types of school children. These findings are consistent with earlier studies [19,20,42,43]. A significant difference was seen between schools on interest/enjoyment and fitness factors. It was observed that government school children showed more interest/enjoyment and fitness than their counterpart private school children. Enjoyment is one of the main motivational factors and an important asset in driving the children towards involvement in sport. This factor is aligned with Weinberg and Gould [44] who stated the main motive in sport is physical fitness, enjoyment and friendship. This significant difference may be due to private schools giving more importance to academic performance than government schools. Thus the formulated hypothesis was rejected.

In conclusion, the present study identified the important reasons for participation of government and private school children towards physical activities as interest and enjoyment motives followed by competence. The least important reason for participation was social factors for both types of school children. Furthermore, the study revealed a significant difference between the types of school children on interest/enjoyment and fitness factor. Results indicated that government school children were more motivated to do physical activity due to their interest/enjoyment and fitness factors.

\section{REFERENCES}

[1] K. Bosnar, B. Balent. Uvod u psihologiju sporta: Prirucnik za sportske trenere. [Introduction to Psychology of Sports: Manual for sports coaches]. Zagreb: Odjel za izobrazbu trenera Drustvenog veleucilista u Zagrebu i Kinezioloski fakultet Sveucilista u Zagrebu, 2009.

[2] L.M. Barnett, E. Van Beurden, P.J. Morgan, L.O. Brooks, J.R. Beard. Does Childhood Motor Skill Proficiency Predict Adolescent Fitness?, Medicine \& Science in Sports \& Exercise, Vol.40, No. 12, 2137-2144, 2008.

[3] S.J. Biddle, C.J. Wang, N.L. Chatzisarantis, and C.M. Spray. Motivation for Physical Activity in Young People: Entity and Incremental Beliefs about Athletic Ability, Journal of Sports Sciences, Vol.21, No. 12, 973-989, 2003.

[4] J. Fraser-Thomas, J. Côté, J. Deakin. Examining Adolescent Sport Dropout and Prolonged Engagement from a Developmental Perspective, Journal of Applied Sport Psychology, Vol.20, No.3, 318-333, 2008.

[5] D. Gould, S. Tuffey, E. Udry, J. Loehr. Burnout in competitive junior tennis players: II. Qualitative analysis, The Sport Psychologist, Vol.10, 322-340, 1996.

[6] N. Koivula. Sport participation: differences in motivation and actual participation due to gender typing, Journal of Sport Behavior, Vol.22, No.3, 360+, 1999.

[7] A.L. Smith, S. Ullrich-French, E. Walker, K.S. Hurley, and others. Peer relationship profiles and motivation in youth sport, Journal of Sport and Exercise Psychology, Vol.28, No.3, 362, 2006.

[8] H. Tsorbatzoudis, K. Alexandris, P. Zahariadis, and G. Grouios. Examining the relationship between recreational sport participation and intrinsic and extrinsic motivation and amotivation, Perceptual and Motor Skills, Vol. 103, No.2, 363-374, 2006.

[9] J.H. Yan, P. McCullagh. Cultural influence on youth's motivation of participation in physical activity, Journal of Sport Behavior, Vol.27, No.4, 378-390, 2004.

[10] P. Zahariadis, H. Tsorbatzoudis, K. Alexandris. Self-determination in sport commitment, Perceptual and Motor Skills, Vol.102, No.2, 405-420, 2006.

[11] M.R. Weiss, L.M. Petlichkoff. Children's motivation for participation in and withdrawal from sport: Identifying the 
missing links. Pediatric Exercise Science, Vol.1, No.3, 1989.

[12] E.M. Cervello, A. Esearti, J.F. Guzman. Youth sport dropout from the achievement goal theory, PSICOTHEMA, Vol.19, No.1, 65-71, 2007.

[13] J. Whitehead, K.V. Andrée, M.J. Lee. Achievement perspectives and perceived ability: how far do interactions generalize in youth sport?, Psychology of Sport and Exercise, Vol.5, No.3, 291-317, 2004.

[14] M.R. Weiss, E. Ferrer-Caja. Motivational orientations and sport behavior, In Advances in sport psychology, 2nd Ed., pp. 101-170, Human Kinetics, Champaign, IL, US (2002).

[15] S.N. Blair. Physical activity, physical fitness and health, Research Quarterly of Exercise and Sport, Vol.64, No.4, 365-376 (1993).

[16] M.G. Ragheb. Leisure and perceived wellness: A field investigation, Leisure Sciences, Vol.15, No.1, 13-24 (1993).

[17] H.H. Schomer, B.S. Drake. Physical Activity and Mental Health, International SportMed Journal, Vol.2, No.3, 1 (2001).

[18] T.F. Cash, P.L. Novy, J.R. Grant. Why do women exercise? Factor analysis and further validation of the Reasons for Exercise Inventory, Perceptual and Motor Skills, Vol.78, No.2, 539-544 (1994).

[19] J.J.M. Dwyer. Internal structure of participation motivation questionnaire completed by undergraduates, Psychological Reports, Vol.70, No.1, 283-290 (1992).

[20] S.E. Flood, J.C. Hellstedt. Gender differences in motivation for intercollegiate athletic participation, Journal of Sport Behavior, Vol.14, No.3, 159-167 (1991).

[21] C.M. Frederick, R.M. Ryan. Differences in motivation for sport and exercise and their relations with participation and mental health, Journal of Sport Behavior, Vol.16, No.3, 124-146 (1993).

[22] K. Gill, V. Overdorf. Incentives for exercise in younger and older women, Journal of Sport Behavior, Vol.17, No.2, 87-97 (1994).

[23] J.L. Duda, M.K. Tappe. Personal investment in exercise among adults: The examination of age and gender-related differences in motivational orientation, Aging and Motor Behavior, 239-256 (1989).

[24] D. Markland, L. Hardy. The exercise motivations inventory: Preliminary development and validity of a measure of individuals' reasons for participation in regular physical exercise, Personality and Individual Differences, Vol.15, No.3, 289-296 (1993).

[25] Canada Fitness Survey. The Ontario curriculum, Grade 11 and 12, Ministry of Education, Ontario, Canada (1983).

[26] J. Knapen, D. Vancampfort, B. Schoubs, M. Probst, P. Sienaert, P. Haake, J. Peuskens, and G. Pieters. Exercise for the treatment of depression, The Open Complementary Medicine Journal, Vol.1, 78-83 (2009).

[27] D.E.R. Warburton, C.W. Nicol, S.S.D. Bredin. Prescribing exercise as preventive therapy, Canadian Medical Association Journal, Vol.174, No.7, 961-974 (2006).
[28] J.L. Duda. Motivation in sport settings: A goal perspective approach., in: Ed. by G.C. Roberts, Motiv. Sport Exerc., pp. 57-91, Human Kinetics Books, Champaign, IL (1992).

[29] J. Fang. Research on motivation, attribution, self-efficacy and sport learning effects, Journal of Beijing Sport University, Vol.30, 1691-1692 (2007).

[30] M. Goudas and M. Hassandra. Greek Students' Motives for Participation in Physical Education, International Journal of Physical Education, Vol.43, No.2, 85-89 (2006).

[31] V.N. Irkhin and O.V. Mikhaylova. Formation of students' motivation to physical culture occupations based on kinesiological approach, Теория и практика физической культуры [Theory and Practice of Physical Culture], Vol.9, 56-60 (2007).

[32] R.S. Lutz, P. Karoly, and M.A. Okun. The why and the how of goal pursuit: Self-determination, goal process cognition, and participation in physical exercise, Psychology of Sport and Exercise, Vol.9, No.5, 559-575 (2008).

[33] M. Standage and F. Gillison. Students' motivational responses toward school physical education and their relationship to general self-esteem and health-related quality of life, Psychology of Sport and Exercise, Vol.8, No.5, 704-721 (2007).

[34] J. Strel and B. Sila. Sportne dejavnosti slovenske mladine med 15. in 18. letom starosti [Sport activity of Slovenian adolescents aged between 15 and 18], Sport, Vol.58, 124-129 (2010).

[35] A.M. Guest. Cultural meanings and motivations for sport: A comparative case study of soccer teams in the United States and Malawi, Athletic Insight - The Online Journal of Sport Psychology, Vol.9, No.1, 1-18 (2007).

[36] R.M. Ryan, C.M. Frederick, D. Lepes, N. Rubio. Intrinsic motivation and exercise adherence, International Journal of Sport Psychology, Vol.28, No.4, 335-354 (1997).

[37] E. Caglar, Y. Canlan, M. Demir. Recreational Exercise Motives of Adolescents and Young Adults, Journal of Human Kinetics, Vol.22, 83-89 (2010).

[38] L. Gauvin. An experiential perspective on the motivational features of exercise and lifestyle, Canadian Journal of Sport Sciences, Vol.15, No.1, 51-58 (1990).

[39] M.R. Leary. Self-presentational processes in exercise and sport, Journal of Sport and Exercise Psychology, Vol.14, 339-339 (1992).

[40] D.K. Ingledew, G. Sullivan. Effects of body mass and body image on exercise motives in adolescence, Psychology of Sport and Exercise, Vol.3, No.4, 323-338 (2002).

[41] Y.H. Kim, H.K. Lee. Obese adolescents' physical activity and its related motivational variables, International Journal of Sport Sociology, Vol.2, 47-54 (2011).

[42] D. Gill, J. Gross, S. Huddleston. Participation motivation in youth sports, International Journal of Sports Psychology, Vol.14, No.1, 11-14 (1983).

[43] Raugh, R. Wall. Measuring sports participation motivation, International Journal of Sport Psychology, Vol.18, No.2, 112-119 (1987)

[44] R. Weinberg, D. Gould. Foundations of Sport and Exercise Psychology, 4 edition, Human Kinetics, Champaign, IL (2006). 